\title{
Evidence for left ventricular dysfunction in patients with obstructive sleep apnoea syndrome
}

\author{
M. Alchanatis*, G. Tourkohoriti*, E.N. Kosmas*, G. Panoutsopoulos\#, S. Kakouros ${ }^{\star}$, K. Papadima*, \\ M. Gaga*, J.B. Jordanoglou*
}

Evidence for left ventricular dysfunction in patients with obstructive sleep apnoea syndrome. M. Alchanatis, G. Tourkohoriti, E.N. Kosmas, G. Panoutsopoulos, S. Kakouros, K. Papadima, M. Gaga, J.B. Jordanoglou. C) ERS Journals Ltd 2002.

ABSTRACT: There is limited information on the development of left ventricular (LV) dysfunction in patients with obstructive sleep apnoea (OSA) in the absence of lung and cardiac comorbidity. This study aimed to investigate whether OSA patients without heart morbidity develop LV dysfunction, and to assess the effect of continuous positive airway pressure (CPAP) on LV function.

Twenty-nine OSA patients and 12 control subjects were studied using technetium99m ventriculography to estimate $L V$ ejection fraction (LVEF), $L V$ peak emptying rate (LVPER), time to peak emptying rate (TPER), peak filling rate (LVPFR) and time to peak filling rate (TPFR) before and after 6 months of treatment with CPAP.

A significantly lower LVEF was found in OSA patients, compared to control subjects, $(53 \pm 7$ versus $61 \pm 6 \%)$ along with a reduced LVPER $(2.82 \pm 0.58$ versus $3.82 \pm 0.77$ end-diastolic volumes $\left.\cdot \mathbf{s}^{-1}\right)$. Furthermore, OSA patients had significantly lower LVPFR $\left(2.67 \pm 0.71\right.$ versus $3.93 \pm 0.58$ end-diastolic volumes $\left.\cdot s^{-1}\right)$ and delayed TPFR (0.19 \pm 0.04 versus $0.15 \pm 0.03 \mathrm{~s})$ in comparison with the control group. Sixmonths of CPAP treatment was effective in significantly improving LVEF, LVPER, LVPFR and TPFR.

In conclusion, obstructive sleep apnoea patients without any cardiovascular disease seem to develop left ventricular systolic and diastolic dysfunction, which may be reversed, either partially or completely, after 6 months of continuous positive airway pressure treatment.

Eur Respir J 2002; 20: 1239-1245.

\author{
*Pulmonary Dept, Athens University \\ Medical School, "Nuclear Medicine \\ Dept, and Cardiology Department, \\ "Sotiria" Hospital for Chest Diseases, \\ Athens, Greece. \\ Correspondence: M. Alchanatis \\ 10 Mpakopoulou Str. \\ 15451 Athens \\ Greece \\ Fax: 30107770423 \\ E-mail: enkosmas@mland.gr \\ Keywords: Cardiovascular disease \\ continuous positive airway pressure \\ ejection fraction \\ left ventricular function \\ obstructive sleep apnoea
}

Received: September 62001

Accepted after revision: June 112002
Cardiovascular disturbances are the most serious complications of the obstructive sleep apnoea (OSA) syndrome. These complications include systemic hypertension, acute myocardial infarction, nocturnal arrhythmias, cor pulmonale and sudden nocturnal death [1-3]. Other studies have demonstrated an association of OSA with certain cases of left ventricular (LV) failure of otherwise unknown aetiology $[4,5]$. In addition, it is possible that the presence of OSA in patients with coexisting cardiac or pulmonary disease, promotes the appearance or the deterioration of LV failure [6].

Clearly, it is important to show whether OSA alone constitutes an independent risk factor for the development of LV dysfunction and, thus, for increased cardiovascular morbidity and mortality. The authors have shown recently that impaired LV diastolic filling, as assessed by pulsed Doppler echocardiography, occurs in awake OSA patients with no other active pulmonary or cardiac disease [7]. However, there is limited information on the development of LV dysfunction in the absence of lung or heart comorbidity and on the response of LV function indices to treatment with nasal continuous positive airway pressure (CPAP).
Hence, the aims of this study were two-fold: first, to investigate the possibility that OSA patients with no other active cardiac or lung disease show LV systolic and/or diastolic dysfunction; and secondly, to assess the effect of CPAP treatment on LV function.

\section{Patients and methods}

\section{Study population}

Patients who were enrolled in the study fulfilled the following inclusion criteria: 1) polysomnographic diagnosis of OSA with an apnoea/hypopnoea index (AHI) $>15$ events $\cdot \mathrm{h}^{-1}$; 2) absence of cardiac comorbidity (such as left heart failure, cor pulmonale, systemic hypertension, cardiomyopathy, myocardial disease, pericardial disease, valvular disease and arrythmias), based on both clinical examination and routine cardiological evaluation (chest radiograph, electrocardiogram, echocardiography); 3) no clinical or laboratory (chest radiograph, lung function testing) evidence of lung disease; 4) daytime normoxaemia and normocapnia; and 5) compliance to CPAP treatment. The study was approved by the Institutional 
Ethics Committee and an informed consent was obtained by all patients and control subjects.

The population of the study consisted of patients referred to the Sleep Laboratory of the Pulmonary Dept, Athens University Medical School (Athens, Greece), because of snoring, excessive daytime sleepiness, or suspected OSA syndrome. Between January 1999 and March 2000, 38 consecutive patients met the inclusion criteria. During the follow-up period, one patient died, three patients did not comply with CPAP treatment after the second month and five patients refused to repeat estimation of $\mathrm{LV}$ function following 6 months of CPAP treatment. Finally, a total of 29 eligible patients (19 males and 10 females) aged $51 \pm 10$ yrs (mean \pm SD), who satisfied the above mentioned inclusion criteria and agreed to participate, were included in the study. In addition, 12 normal subjects (seven males, five females) referred to the laboratory for snoring but without proven OSA (AHI $<10$ events $\cdot h^{-1}$ ), and matched for age, body mass index (BMI) and smoking history, were included in the study as the control group.

\section{Study procedure}

Patients gave a detailed medical history and were clinically examined. They underwent arterial blood gas analysis and spirometry pre- and postbronchodilation. All patients had a resting oxygen tension in arterial blood $\geqslant 10 \mathrm{kPa}$ and carbon dioxide tension in arterial blood $\leqslant 6 \mathrm{kPa}$. Spirometric values of forced expiratory volume in one second (FEV1) and forced vital capacity (FVC) $<80 \%$ of predicted, a $\mathrm{FEV} 1 / \mathrm{FVC}$ ratio $<75 \%$ or a post-bronchodilator increase in FEV1 $>10 \%$ of baseline value, were all considered as exclusion criteria.

Furthermore, all subjects underwent a routine cardiological evaluation (blood pressure measurement, electrocardiogram, echocardiography) in order to rule out patients with primary heart disease. None of the studied patients had a history of either arterial hypertension or use of antihypertensive medications. Hypertension was defined as a blood pressure measurement $>140 \mathrm{mmHg}$ systolic and/or $90 \mathrm{mmHg}$ diastolic pressure. Cut-off values for echocardiographic evaluation of left ventricular function were: end-diastolic LV diameter $56 \mathrm{~mm}$, end-systolic LV diameter $38 \mathrm{~mm}$, fractional shortening $0.28-0.32$, enddiastolic LV posterior wall thickness $11 \mathrm{~mm}$, and enddiastolic interventricular septum thickness $11 \mathrm{~mm}$.

Full-night diagnostic polysomnography (Medilog $\mathrm{SAC}$, Oxford, UK), with recordings of electroencephalogram (C4/A1, C3/A2), electrooculogram, chin electromyogram, electrocardiogram, nasal and mouth flow, rib cage and abdominal wall displacement, oxygen saturation and snoring, was performed in all patients and control subjects according to internationally approved methods [8]. In addition, blood pressure was measured just before bedtime and immediately after awakening.

The day after the polysomnography, LV function was assessed in all patients and control subjects by radionuclide ventriculography (RVG), using the first-pass and the equilibrium method with technetium-99m $\left({ }^{99 \mathrm{~m}} \mathrm{Tc}\right)$ attached to red blood cells as the radioactive intravascular indicator. Counts were recorded with a $\gamma$-camera (Gamma-Diagnostics, Phillips, Germany) in three views (left anterior oblique, left posterior oblique, anterior) in the supine position from $\sim 1,000$ cardiac cycles following uniform distribution of radiotracer. Analysis was performed using a commercially available software package and all studies were interpreted by an experienced nuclear physician blinded to the patients' sleep data. Systolic LV function was estimated using the left ventricular ejection fraction (LVEF), the LV peak emptying rate (LVPER) and the time to LVPER (TPER), while LV diastolic function was assessed by the LV peak filling rate (LVPFR) and the time to LVPFR (TPFR). A LVEF value $>55 \%$ of end-diastolic volume (LVED), a LVPFR $\geqslant 2.5$ $\mathrm{LVED} \cdot \mathrm{s}^{-1}$ and a TPFR $<0.18 \mathrm{~s}$ were taken to indicate normal systolic and diastolic LV function.

All OSA patients underwent a second full-night polysomnography with CPAP for titration of the optimal pressure needed to eliminate apnoeas, hypopnoeas and oxygen desaturation episodes. During the next day, patients were discharged from the hospital and a nasal CPAP device, equipped with an internal time counter, was given for treatment at home. During the treatment period, all patients were followed up on a monthly basis at the outpatient Sleep Clinic, with the daily usage of CPAP assessed according to the internal time counter. The difference in time counter readings in hours divided by the duration of the treatment in days was used for the estimation of the mean daily use of CPAP at every visit. At the end of the study the mean daily CPAP usage was $5.9 \mathrm{~h} \cdot$ night $^{-1}$ (range $4.6-8.0 \mathrm{~h} \cdot$ night $^{-1}$ ).

After 6 months of CPAP treatment, all OSA patients were re-evaluated with full-night polysomnography, arterial blood gas analysis, pulmonary function testing and ${ }^{99 \mathrm{~m}}$ Tc-RVG for the re-estimation of the $\mathrm{LV}$ function indices.

\section{Statistical analysis}

Measurements are expressed as mean \pm SD. Results were analysed using unpaired t-tests for comparisons between OSA patients and control subjects, and paired t-tests for comparisons between LV function indices before and after CPAP treatment in OSA patients. Linear regression analysis with Pearson's coefficients was used to assess the strength of association between variables. Statistical significance was set at $\mathrm{p}<0.05$.

\section{Results}

Anthropometric, lung function, sleep study data and blood pressure in OSA patients and control nonapnoeic snorers are shown in table 1 . No statistical differences were observed with respect to age, BMI, blood pressure and lung function indices between patients and control subjects. 
Table 1.-Anthropometric characteristics, lung function data, blood pressure and sleep data in obstructive sleep apnoea (OSA) patients and control subjects

OSA patients Control subjects p-value

\begin{tabular}{lccc}
\hline Subjects n & 29 & 12 & \\
Age yrs & $51 \pm 10$ & $53 \pm 6$ & NS \\
$\mathrm{BMI} \mathrm{kg} \cdot \mathrm{m}^{-2}$ & $34 \pm 6$ & $30 \pm 3$ & $\mathrm{NS}$ \\
$\mathrm{FEV} 1 \%$ pred & $92 \pm 13$ & $91 \pm 5$ & $\mathrm{NS}$ \\
$\mathrm{FVC} \mathrm{\%} \mathrm{pred}$ & $91 \pm 12$ & $88 \pm 6$ & $\mathrm{NS}$ \\
$\mathrm{FEV} 1 / \mathrm{FVC} \%$ & $79 \pm 4$ & $84 \pm 6$ & $\mathrm{NS}$ \\
$\mathrm{Pa}, \mathrm{O}_{2} \mathrm{kPa}$ & $12.0 \pm 1.3$ & $12.0 \pm 0.5$ & $\mathrm{NS}$ \\
$\mathrm{Pa}, \mathrm{CO}_{2} \mathrm{kPa}$ & $5.3 \pm 0.5$ & $5.2 \pm 0.4$ & $\mathrm{NS}$ \\
$\mathrm{AHI}$ events$\cdot \mathrm{h}^{-1}$ & $54 \pm 19$ & $9 \pm 2$ & $<0.001$ \\
Desaturation & $232 \pm 100$ & $22 \pm 13$ & $<0.001$ \\
$\quad$ events $\cdot \mathrm{TST}^{-1}$ & & & \\
Lowest $\mathrm{Sa}_{\mathrm{a}} \mathrm{O}_{2} \%$ & $62 \pm 12$ & $92 \pm 6$ & $<0.001$ \\
Average $\mathrm{Sa}_{2} \mathrm{O}_{2} \%$ & $81 \pm 10$ & $95 \pm 2$ & $<0.001$ \\
BP s/d mmHg & $137 \pm 7 / 91 \pm 11$ & $131 \pm 5 / 87 \pm 9$ & $\mathrm{NS}$
\end{tabular}

Data are presented as mean \pm SD. BMI: body mass index; FEV1: forced expiratory volume in one second; FVC: forced vital capacity; $\mathrm{Pa}, \mathrm{O}_{2}$ : oxygen tension in arterial blood; $P \mathrm{a}, \mathrm{CO}_{2}$ : carbon dioxide tension in arterial blood; $\mathrm{AHI}$ : apnoea/hypopnoea index; TST: total sleep time; $\mathrm{Sa}_{\mathrm{a}} \mathrm{O}_{2}$ : arterial oxygen saturation; Desaturation: $S_{\mathrm{a}, \mathrm{O}_{2}}$ drop at least 4\%; BP: blood pressure immediately after awakening; s/d: systolic/diastolic. NS: nonsignificant.

\section{Pretreatment systolic left ventricular function}

Eighteen of the 29 OSA patients had an abnormal LVEF $<55 \%$ while only one control subject had LVEF $<55 \%$. Mean LVEF was $53 \pm 7 \%$ in OSA patients and $61 \pm 6 \%$ in control subjects $(\mathrm{p}=0.003)$. A statistically significant difference between OSA patients and nonapnoeic snorers was also evident in LVPER (2.82 \pm 0.58 versus $3.82 \pm 0.77 \quad \mathrm{LVED} \cdot \mathrm{s}^{-1}$, respectively; $\mathrm{p}<0.001)$. However, there was no difference in TPER between OSA patients and control subjects $(0.32 \pm 0.31$ versus $0.30 \pm 0.31 \mathrm{~s}$, respectively; table 2).

No correlation was found between systolic LV function indices and severity of OSA (AHI) or

Table 2. - Comparison in pretreatment (baseline) systolic and diastolic left ventricular (LV) function indices between obstructive sleep apnoea (OSA) patients and control subjects (nonapnoeic snorers)

\begin{tabular}{lccc}
\hline & $\begin{array}{c}\text { OSA } \\
\text { patients }\end{array}$ & $\begin{array}{c}\text { Control } \\
\text { subjects }\end{array}$ & p-value \\
\hline $\begin{array}{l}\text { Subjects n } \\
\text { Systolic LV function }\end{array}$ & 29 & 12 & \\
$\quad$ LVEF \% & $53 \pm 7$ & $61 \pm 6$ & 0.003 \\
LVPER LVED·s ${ }^{-1}$ & $2.82 \pm 0.58$ & $3.82 \pm 0.77$ & $<0.001$ \\
TPER s & $0.32 \pm 0.31$ & $0.31 \pm 0.30$ & NS \\
Diastolic LV function & & & \\
$\quad$ LVPFR LVED·s & \\
TPFR s & $2.67 \pm 0.71$ & $3.93 \pm 0.58$ & $<0.001$ \\
& $0.19 \pm 0.04$ & $0.15 \pm 0.03$ & 0.002
\end{tabular}

Data are presented as mean \pm SD. LVEF: left ventricular ejection fraction; LVPER: left ventricular peak emptying rate; LVED: left ventricular end-diastolic volume; TPER: time to peak emptying rate; LVPFR: left ventricular peak filling rate; TPFR: time to peak filling rate. NS: nonsignificant. desaturation during sleep (number of desaturation events, nadir and average arterial oxygen saturation $\left.\left(\mathrm{Sa}, \mathrm{O}_{2}\right)\right)$.

\section{Pretreatment diastolic left ventricular function}

Fourteen of the 29 OSA patients had an abnormally low value of LVPFR (cut-off level $2.5 \mathrm{LVED} \cdot \mathrm{s}^{-1}$ ) and 18 of the 29 had an abnormally high value of TPFR (cut-off level $0.18 \mathrm{~s}$ ). In only six of the 29 OSA patients were both indices of LV function within normal limits, while the remaining 23 patients showed diastolic LV dysfunction. In contrast, only two of the 12 control subjects had a TPFR value $>0.18 \mathrm{~s}$ and none had LVPFR $<2.5 \mathrm{LVED} \cdot \mathrm{s}^{-1}$. In comparison with nonapnoeic snorers, OSA patients had significantly lower LVPFR values $(3.93 \pm 0.58$ versus $2.67 \pm 0.71 \mathrm{LVED} \cdot \mathrm{s}^{-1}$, respectively; $\left.\mathrm{p}<0.001\right)$ and higher TPFR $(0.15 \pm 0.03$ versus $0.19 \pm 0.04 \mathrm{~s}$, respectively; $\mathrm{p}=0.002$ ) (table 2 ).

No correlation was found between diastolic LV function indices and severity of OSA (AHI) or nocturnal desaturation (number of desaturation events, nadir and average $\left.\mathrm{Sa}_{\mathrm{a}} \mathrm{O}_{2}\right)$.

Effect of continuous positive airway pressure on systolic and diastolic left ventricular function

The beneficial impact of 6 months of CPAP treatment, shown in all LV systolic and diastolic functional indices, is shown in table 3 . It has to be noted that the LVEF, LVPER and LVPFR, although improved, in comparison with the pretreatment values, were still lower than the values in the control subjects. Interestingly, CPAP seems to affect the diastolic LV function more favourably, since after CPAP only four of the 29 patients still had LVPFR $<2.5 \mathrm{LVED} \cdot \mathrm{s}^{-1}$ and only one of the 29 patients had a TPFR $>0.18 \mathrm{~s}$. In total, 18 of the 23 patients with

Table 3.-Systolic and diastolic left ventricular (LV) function indices, body mass index (BMI) and blood pressure (BP) in obstructive sleep apnoea patients before and after 6 months of continuous positive airway pressure (CPAP) treatment

\begin{tabular}{lccc}
\hline & $\begin{array}{c}\text { Before CPAP } \\
\text { treatment }\end{array}$ & $\begin{array}{c}\text { After CPAP } \\
\text { treatment }\end{array}$ & p-value \\
\hline Systolic LV function & & & \\
LVEF \% & $53 \pm 7$ & $56 \pm 6$ & $<0.001$ \\
LVPER LVED $\mathrm{s}^{-1}$ & $2.82 \pm 0.58$ & $3.18 \pm 0.55$ & 0.009 \\
TPER s & $0.32 \pm 0.31$ & $0.20 \pm 0.17$ & $\mathrm{NS}$ \\
Diastolic LV function & & & \\
LVPFR LVED·s ${ }^{-1}$ & $2.67 \pm 0.71$ & $3.14 \pm 0.71$ & 0.006 \\
TPFR s & $0.19 \pm 0.04$ & $0.13 \pm 0.02$ & $<0.001$ \\
BMI kg $\mathrm{m}^{-2}$ & $34 \pm 6$ & $32 \pm 4$ & $\mathrm{NS}$ \\
BP s/d mmHg & $137 \pm 7 / 91 \pm 11$ & $136 \pm 5 / 86 \pm 8$ & $\mathrm{NS}$ \\
\hline
\end{tabular}

Data are presented as mean \pm SD. LVEF: left ventricular ejection fraction; LVPER: left ventricular peak emptying rate; LVED: left ventricular end-diastolic volume; TPER: time to peak emptying rate; LVPFR: left ventricular peak filling rate; TPFR: time to peak filling rate; s/d: systolic/ diastolic. NS: nonsignificant. 
previous LV diastolic dysfunction gained normal diastolic LV function following the CPAP treatment. In contrast, the LVEF recovered to normal levels in only five patients and remained abnormally low $(<55 \%)$ in 13 of the 18 OSA patients with pretreatment systolic LV dysfunction. Importantly, BMI and blood pressure measured immediately after awakening, did not change during the treatment period (table 3 ).

The individual changes of LVEF, LVPER, LVPFR and TPFR between pre- and post-CPAP treatment in the 29 OSA patients are shown in fig. 1.

\section{Discussion}

The main findings of this study are: 1) the majority of the studied patients with OSA syndrome, and no other primary lung or cardiac disease, exhibited mild-to-moderate decreases in LVEF and LVPFR, suggestive of systolic and diastolic LV dysfunction, respectively; 2) systolic and diastolic LV dysfunction in the studied OSA patients could not be attributed to the usual causes of LV functional disturbances, such as coronary artery disease, congestive heart failure (CHF) due to a cardiomyopathy or valvular heart disease (for systolic LV dysfunction), chronic systemic hypertension with LV hypertrophy, hypertrophic cardiomyopathy or aortic stenosis (for diastolic LV function); 3) systolic and diastolic LV dysfunction did not correlate with the severity of OSA or the severity of nocturnal arterial desaturation; and 4) treatment with nasal CPAP for at least 6 months resulted in consistent and statistically significant recovery of systolic, but more so of diastolic, $\mathrm{LV}$ functional indices towards normal.

It is widely acknowledged that LV systolic and diastolic function can be assessed with confidence using RVG. RVG was first introduced in the 1970s and quickly became accepted as the preferred technique for measurement of LVEF, with a high degree of accuracy. Several early studies demonstrated excellent correlations of RVG-derived LVEF with values obtained by cardiac catheterisation-contrast ventriculography. Advantages of RVG include high reproducibility and low inter- and intra-observer variability $(<5 \%)$. RVG is considered the most reproducible test for the assessment of LV systolic function [9]. Reliable information about LV diastolic performance can also be obtained from RVG, although it requires more details than that used for calculating the LVEF. Cardiac frequency variability and premature beats make the recording of diastolic data problematic and
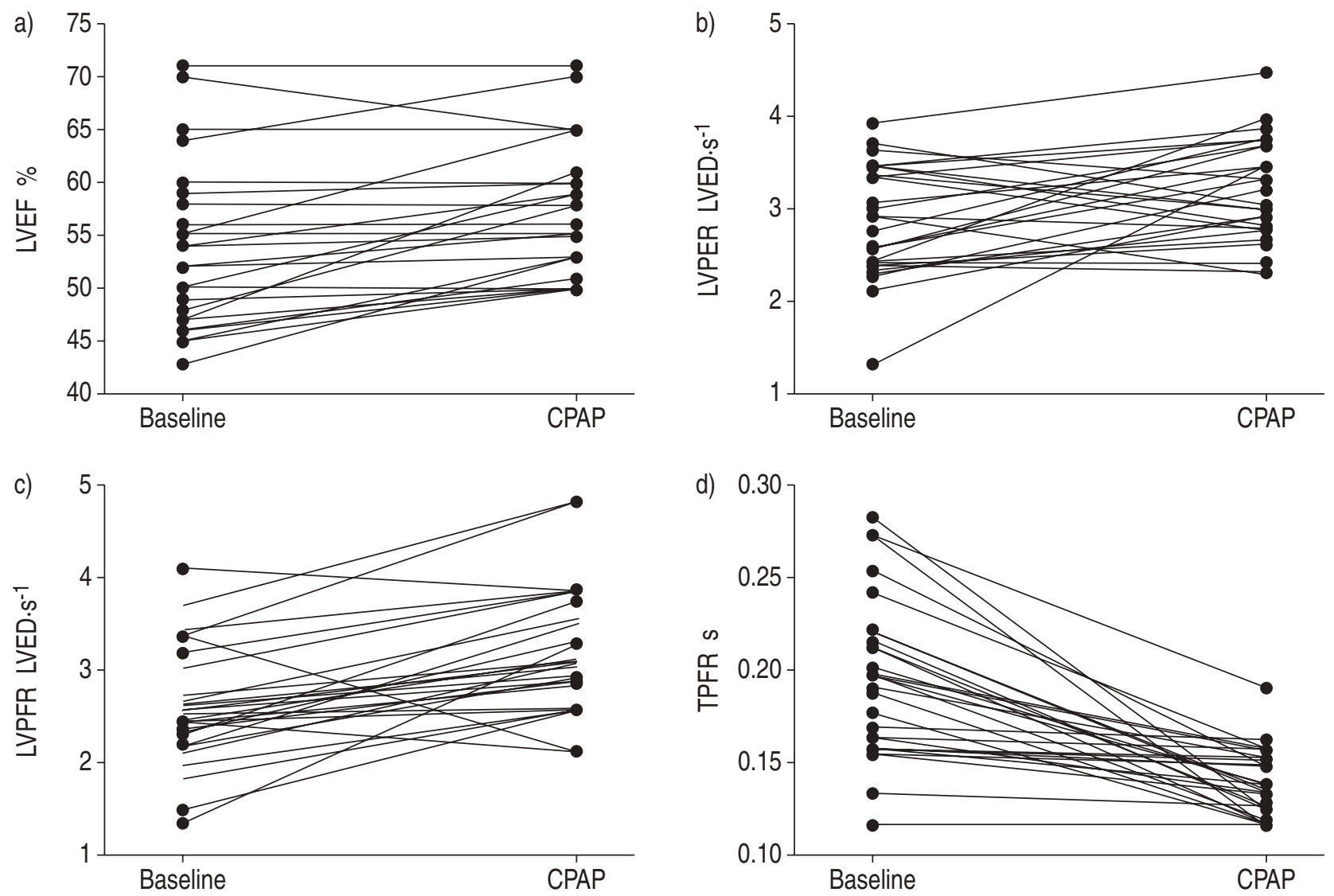

Fig. 1.-Individual changes in a) left ventricular ejection fraction (LVEF), b) left ventricular peak emptying rate (LVPER), c) left ventricular peak filling rate (LVPFR) and d) time to peak filling rate (TPFR) before and after 6 months of continuous positive airway pressure (CPAP) treatment. It is obvious that CPAP treatment results in an improvement in all indices in the vast majority of obstructive sleep apnoea (OSA) patients with pretreatment left ventricular dysfunction. Each line, point-to-point, represents the change before and after CPAP in each OSA patient. 
many beats may need to be rejected. Therefore, a high frame-rate acquisition must be employed and the data must be mathematically smoothed and averaged. Because of the large amount of data required for more accurate assessment of diastolic function, equilibrium RVG is the preferred mode. In addition to RVG, diastolic function can be assessed noninvasively by M-mode echocardiography and Doppler echocardiography and invasively by contrast ventriculography. A number of studies have examined the correlation between these techniques and RVG. Both $\mathrm{RVG}$-derived indices of $\mathrm{LV}$ diastolic function, i.e. peak filling rate and TPFR, were strongly correlated with the indices derived by the other techniques. Therefore, RVG is considered as an equally reliable method of assessing LV diastolic function as echocardiography and contrast ventriculography [10].

OSA is characterised by the occurrence of episodes of complete or partial upper airway obstruction during sleep. Prevalence surveys estimate that $2 \%$ of females and $4-5 \%$ of males of middle age are affected by this syndrome [11]. OSA has been recognised increasingly as an important medical condition, producing severe morbidity and appreciable mortality $[6,12]$, while the most relevant long-term consequences of OSA arise from its cardiovascular morbidity. Cardiovascular disturbances are the most serious complications of the OSA syndrome, and include systemic hypertension, acute myocardial infarction, nocturnal arrhytmias, cor pulmonale and sudden nocturnal death [1-3].

There is compelling evidence that the pathophysiological basis of cardiovascular morbidity in OSA syndrome stems from the repetitive haemodynamic oscillations experienced by patients during the night. Changes in systemic arterial blood pressure, pulmonary artery pressure, cardiac frequency, stroke volume and cardiac output occur in association with alterations in sleep state and breathing [13-15]. Because of these sometimes dramatic, haemodynamic fluctuations following the cyclical episodes of upper airway occlusion and reopening during sleep, investigators have examined the relationship between OSA and impaired cardiac function, but as yet this relationship remains uncertain.

Sleep-disordered breathing and $\mathrm{CHF}$ are both common disorders and there appears to be considerable overlap between the two diseases. Some data suggest that $\sim 40-50 \%$ of stable asymptomatic outpatients with CHF have either OSA or Cheyne-Stoke respiration with central sleep apnoea [16-18]. CHAN et al. [19] evaluated patients with symptomatic (New York Heart Association class II-III) diastolic heart failure, and noted that $55 \%$ of their patients had significant sleep-disordered breathing, mainly obstructive apnoeas. Evidence is also accumulating that sleep-related breathing disorders can contribute to progression of heart failure and affect its prognosis [20], raising the possibility that the presence of OSA in patients with coexisting cardiac disease, accelerates the deterioration of heart failure [6].

Given that there is an obvious association between OSA and CHF, many investigators have addressed the question whether OSA per se can cause CHF. A number of reports implicate OSA alone as an independent risk factor for the development of LV dysfunction and CHF. The first direct evidence that OSA might play a role in provoking LV dysfunction came from HEDNER et al. [21] who reported increased LV wall thickness in normotensive patients with OSA versus normotensive nonapnoeic subjects. KRIEGER et al. [4] studied LVEF in 29 OSA patients without left heart failure, and mean LVEF was found to be at the lower limits of normal. After $1 \mathrm{yr}$ of nasal CPAP treatment, LVEF increased slightly but significantly. The current authors studied 15 OSA patients without cardiac morbidity, using M-mode 2D and pulsed Doppler echocardiography before and after 12 weeks of CPAP treatment, and observed LV diastolic dysfunction which was reversible following CPAP treatment [7]. Of even greater interest were the findings of MALONE et al. [5], who described a group of eight patients with $\mathrm{CHF}$ related to idiopathic dilated cardiomyopathy. Polysomnography showed severe OSA in all, and after 1 month of treatment with CPAP patients experienced dramatic improvements in LV function. LVEF, which was $37 \%$ before treatment, increased to $49 \%$, and was accompanied by improvement in LV functional status. Moreover, withdrawal of CPAP for 1 week resulted in deterioration of LVEF back to pretreatment levels. Such improvements in LVEF were far beyond that normally described with medical therapy for $\mathrm{CHF}$, including vasodilators, diuretics or inotropic agents.

The findings of this study are in close agreement with those of the above mentioned articles. In this study, an impairment of systolic LV function, in terms of decreased LVEF and decreased LVPER, as well as of diastolic LV function in terms of LVPFR and increased TPFR in the majority of the studied OSA patients was documented compared with control nonapnoeic snorers. Furthermore, it was found that 6 months of CPAP treatment resulted in substantial improvements in all systolic and diastolic LV functional parameters. However, it should be recognised that the lack of a control group of OSA patients treated with placebo (sham) CPAP, constitutes a limitation of the study. Such an evaluation (sham versus therapeutic CPAP) would have been more appropriate to assess the improvement in LV function following effective CPAP treatment. Many investigators have used subtherapeutic levels of CPAP as a placebo treatment in OSA patients [22-29] in order to evaluate the effects of CPAP on sleep architecture, cognitive function, blood pressure, neuropsychological function, cardiac autonomic function, sympathetic nervous system activity etc. Among these randomised and placebo CPAP-controlled studies, there are some assessing the effect of CPAP on various indices of cardiac function. FACCENDA et al. [23] observed that CPAP can reduce blood pressure in OSA patients, particularly in those with nocturnal oxygen desaturation, but the decrease was small. Moreover, Neleson et al. [25] have shown that after 1 week of CPAP treatment in OSA patients, many pretreatment indicators of poor cardiac function, such as contractility, parasympathetic activity and haemodynamics, are improved. In this study, sham 
CPAP was not used as a placebo treatment. However, the authors believe that the changes in LV functional indices observed after the 6-month CPAP treatment were most likely induced by the CPAP and were not irrelevant. As is evident from the current results from individual patients, the impact of CPAP on diastolic LV function, in particular, appears to be consistent.

It is of interest that obesity did not seem to play a role in the development of LV dysfunction in this study, since the OSA patients and control subjects had similar BMI and the body weight of OSA patients did not fall significantly during CPAP treatment. Thus, the current results are not in agreement with those of LAABAN et al. [30], who demonstrated that the moderate LV hypertrophy they found was not related to OSA but rather to massive obesity. However, the subjects in this study had a BMI $\left(\sim 50 \mathrm{~kg} \cdot \mathrm{m}^{-1}\right)$, much greater than the present patients (averaging $34 \mathrm{~kg} \cdot \mathrm{m}^{-2}$ ), and a lower AHI $(38 \pm 24$ events $\cdot h^{-1}$ ) as compared to the subjects in the present study $\left(54 \pm 19\right.$ events $\left.\cdot \mathrm{h}^{-1}\right)$. It is reasonable to assume that the hazardous consequences of morbid obesity on LV function rival the effects of mild OSA in the patient group of the study by LAABAN et al. [30].

The pathophysiological mechanisms responsible for the OSA-related LV dysfunction are probably the combined detrimental effects on cardiovascular function attributed to a triad of factors: the large negative intrathoracic pressure swings against the occluded upper airway; the gas exchange abnormalities; and the repetitive arousals from sleep [20]. Large negative intrathoracic pressures are responsible for the increased left ventricular systolic transmural pressure (afterload) and the reduced stroke volume and cardiac output. Hypoxaemia and hypercapnia result in increased respiratory drive and sympathetic nervous system activity, pulmonary vasoconstriction and hypertension leading to increased right ventricular afterload, systemic vasoconstriction and hypertension and cardiac arrhythmias. However, no correlation between LV dysfunction indices and severity of nocturnal desaturation was observed. Finally, arousals have been associated with increased sympathetic nervous system activity, increased systemic blood pressure and increased cardiac frequency. Recently, the concept of endothelial dysfunction of systemic resistance vessels has been developed. It has been shown that the flow-mediated dilation in large arteries, which depends to a high extent on the endothelial generation of nitric oxide, gradually deteriorates with increasing degree of nocturnal hypoxaemia [31]. Such a deterioration of the nitric oxide-dependent dilatory capacity of the arterial walls, which is induced by the apnoea-related repetitive episodes of nocturnal hypoxaemia, may play a role in the development of LV dysfunction.

In conclusion, the present study has demonstrated that a significant proportion of obstructive sleep apnoea patients without any other active lung or cardiac disease develop left ventricular systolic and diastolic dysfunction compared with nonapnoeic snorers of similar body mass index. Effective treatment with continuous positive airway pressure remarkably improves the left ventricular diastolic function while there is a beneficial effect on left ventricular ejection fraction as well. In addition, obesity does not seem to play a major role in the pathogenesis of left ventricular dysfunction. It seems that obstructive sleep apnoea alone is an independent risk factor for the development of left ventricular dysfunction in the absence of systemic hypertension and without any impact of the obesity.

\section{References}

1. Bradley TD. Right and left ventricular functional impairment and sleep apnea. Clin Chest Med 1992; 13: 459-479.

2. Carlson JT, Hedner JA, Ejnell H, Peterson LE. High prevalence of hypertension in sleep apnea patients independent of obesity. Am J Respir Crit Care Med 1994; 150: 72-77.

3. Hung J, Whitford EG, Parsons RW, Hillman DR. Association of sleep apnea with myocardial infarction in men. Lancet 1990; 336: 261-264.

4. Krieger J, Grucker D, Sforza E, Chambron J, Kurtz D. Left ventricular ejection fraction in obstructive sleep apnea. Effects of long-term treatment with nasal continuous positive airway pressure. Chest 1991; 100: 917-921.

5. Malone S, Liu P, Holloway R, Bradley TD. Obstructive sleep apnoea in patients with dilated cardiomyopathy: effects of continuous positive airway pressure. Lancet 1991; 338: 1480-1484.

6. Marrone O, Bonsignore MR, Insalaco G, Bonsignore $\mathrm{G}$. What is the evidence that obstructive sleep apnoea is an important illness? Monaldi Arch Chest Dis 1998; 53: 630-639.

7. Alchanatis M, Paradellis G, Pini H, Tourkohoriti G, Jordanoglou J. Left ventricular function in patients with obstructive sleep apnoea syndrome before and after treatment with nasal CPAP. Respiration 2000; 67: 367-371.

8. American Thoracic Society - Medical Section of the American Lung Association. Indications and standards for cardiopulmonary sleep studies. Am Rev Respir Dis 1989; 139: 559-568.

9. Danias PG, Heller GV. Noninvasive methods for measurement of left ventricular systolic function. UpToDate $\mathbb{R}$, http://www.uptodate.com. 2001.

10. Pentz WH. Radionuclide assessment of diastolic function. UpToDate $\mathbb{R}$, http://www.uptodate.com. 2001.

11. Young T, Palta M, Dempsey J, Skatrud J, Weber S, Badr S. The occurrence of sleep-disordered breathing among middle-age adults. $N$ Engl J Med 1993; 28: 1230-1235

12. Partinen M, Jamieson A, Guilleminault C. Long-term outcome for obstructive sleep apnea syndrome patients. Chest 1988; 94: 1200-1204.

13. Podszus T, Mayer J, Penzel T, Peter JH, von Wichert P. Nocturnal hemodynamics in patients with sleep apnea. Eur J Respir Dis 1986; 146: 435-439.

14. Shepard JW Jr. Cardiorespiratory changes in obstructive sleep apnea. In: Kryger MH, Roth T, Dement WC, eds. Principles and Practice of Sleep Medicine, 2nd edn. Philadelphia, WB Saunders Co., 1994; pp. 657-666.

15. Stoohs R, Guilleminault C. Cardiovascular changes 
associated with obstructive sleep apnea syndrome. J Appl Physiol 1992; 72: 583-589.

16. Naughton MT, Bradley TD. Sleep apnea in congestive heart failure. Clin Chest Med 1998; 19: 99-113.

17. Javaheri S, Parker TJ, Wexler L, et al. Occult sleepdisordered breathing in stable congestive heart failure. Ann Intern Med 1995; 122: 487-492.

18. Naughton MT, Liu PP, Benard DC, Goldstein RS, Bradley TD. Treatment of congestive heart failure and Cheyne-Stokes respiration during sleep by CPAP. Am J Respir Crit Care Med 1995; 151: 92-97.

19. Chan J, Sanderson J, Chan W, et al. Prevalence of sleep-disordered breathing in diastolic heart failure. Chest 1997; 111: 1488-1493.

20. Javaheri S, Parker TJ, Liming JD, et al. Sleep apnea in 81 ambulatory male patients with stable heart failure. Circulation 1998; 97: 2154-2159.

21. Hedner J, Ejnell H, Caidahl K. Left ventricular hypertrophy independent of hypertension in patients with obstructive sleep apnea. J Hypertens 1990; 8: 941-946.

22. Engleman HM, Kingshott RN, Martin SE, Douglas NJ. Cognitive function in the sleep apnea/hypopnea syndrome. Sleep 2000; 15: Suppl. 4, S102-S108.

23. Faccenda JF, Mackay TW, Boon NA, Douglas NJ. Randomized placebo-controlled trial of continuous positive airway pressure on blood pressure in the sleep apnea-hypopnea syndrome. Am J Respir Crit Care Med 2001; 163: 344-348.

24. Henke KG, Grady JJ, Kuna JT. Effect of nasal continuous positive airway pressure on neuropsychological function in sleep apnea-hypopnea syndrome. A randomized, placebo-controlled trial. Am J Respir Crit Care Med 2001; 163: 911-917.
25. Neleson RA, Yu H, Ziegler MG, Mills PJ, Clausen JL, Dimsdale JE. Continuous positive airway pressure normalizes cardiac autonomic and hemodynamic responses to a laboratory stressor in apneic patients. Chest 2001; 119: 1092-1101.

26. Bardwell WA, Ancoli-Israel S, Berry CC, Dimsdale JE. Neuropsychological effects of one-week continuous positive airway pressure treatment in patients with obstructive sleep apnea: a placebo-controlled study. Psychosom Med 2001; 63: 579-584.

27. Montserrat JM, Ferrer M, Hernandez L, et al. Effectiveness of CPAP treatment in daytime function in sleep apnea syndrome: a randomized, controlled study with an optimized placebo. Am J Respir Crit Care Med 2001; 164: 608-613.

28. Ziegler MG, Mills PJ, Loredo JS, Ancoli-Israel S, Dimsdale JE. Effect of continuous positive airway pressure and placebo treatment on sympathetic nervous system activity in patients with obstructive sleep apnea. Chest 2001; 120: 887-893.

29. McArdle N, Douglas NJ. Effect of continuous positive airway pressure on sleep architecture in the sleep apnea-hypopnea syndrome: a randomized controlled trial. Am J Respir Crit Care Med 2001; 164: 14591463.

30. Laaban J-P, Cassuto D, Orvoen-Frija E, et al. Cardiorespiratory consequences of sleep apnoea syndrome in patients with massive obesity. Eur Respir $J$ 1998; 11: 20-27.

31. Kraiczi H, Caidahl K, Samuelsson A, Peker Y, Hedner J. Impairment of vascular endothelial function and left ventricular filling: association with the severity of apnea-induced hypoxemia during sleep. Chest 2001; 119: 1085-1091. 